\title{
Sorafenib/MEK inhibitor combination inhibits tumor growth and the Wnt/ק-catenin pathway in xenograft models of hepatocellular carcinoma
}

\author{
HUNG HUYNH ${ }^{1}$, RICHARD ONG ${ }^{1}$, KAH YONG GOH $^{1}$, LIEK YEOW LEE ${ }^{1}$, FLORIAN PUEHLER ${ }^{2}$, \\ ARNE SCHOLZ ${ }^{2}$, OLIVER POLITZ ${ }^{2}$, DOMINIK MUMBERG ${ }^{2}$ and KARL ZIEGELBAUER ${ }^{2}$ \\ ${ }^{1}$ Laboratory of Molecular Endocrinology, Division of Molecular and Cellular Research, National Cancer Centre, \\ Singapore 169610, Republic of Singapore; ${ }^{2}$ R\&D Pharmaceuticals, Bayer AG, D-13353 Berlin, Germany
}

Received September 14, 2018; Accepted January 8, 2019

DOI: 10.3892/ijo.2019.4693

\begin{abstract}
Mutations affecting the Wnt/ $\beta$-catenin pathway have been identified in $26-40 \%$ of hepatocellular carcinoma (HCC) cases. Aberrant activation of this pathway leads to uncontrolled cell proliferation and survival. Thus, identifying Wnt/ $\beta$-catenin pathway inhibitors may benefit a subset of patients with HCC. In the present study, the effects of sorafenib and a MEK inhibitor on tumor growth and Wnt/ $\beta$-catenin signaling in HCC models were evaluated. A $\beta$-catenin mutant and $\beta$-catenin wild-type HCC models were treated once daily with i) $10 \mathrm{mg} / \mathrm{kg}$ sorafenib, ii) $15 \mathrm{mg} / \mathrm{kg}$ refametinib (or $25 \mathrm{mg} / \mathrm{kg}$ selumetinib), or iii) sorafenib/refametinib. Western blotting was employed to determine changes in biomarkers relevant to $\mathrm{Wnt} / \beta$-catenin signaling. Apoptosis, cell proliferation and $\beta$-catenin localization were analyzed by immunohistochemistry. Sorafenib/refametinib markedly inhibited tumor growth and cell proliferation, and caused cell death in naïve and sorafenib-resistant HCC models. Despite similar total $\beta$-catenin levels, significant reductions in phosphorylated (p)-RanBP3 Ser58, $\mathrm{p}-\beta$-catenin Tyr142, active $\beta$-catenin and $\beta$-catenin target genes were observed in sorafenib/refametinib-treated tumors. Greater levels of $\beta$-catenin in sorafenib/refametinib-treated tumors were accumulated at the membrane, as compared with in the control. In vitro, sorafenib/refametinib inhibited the $\mathrm{Wnt} / \beta$-catenin pathway and suppressed Wnt-3A-induced p-low-density lipoprotein receptor-related protein 6 Ser1490, p-RanBP3 Ser58 and $\mathrm{p}-\beta$-catenin Tyr142 in HCC cells. Combination of sorafenib
\end{abstract}

Correspondence to: Professor Hung Huynh, Laboratory of Molecular Endocrinology, Division of Molecular and Cellular Research, National Cancer Centre, 11 Hospital Drive, Singapore 169610, Republic of Singapore

E-mail: cmrhth@nccs.com.sg

Key words: Wnt/ $\beta$-catenin pathway, patient-derived xenograft, hepatocellular carcinoma, sorafenib, MEK inhibitor, refametinib, selumetinib and refametinib inhibits the growth of naïve and sorafenib resistant $\mathrm{HCC}$ tumors in association with active suppression of $\beta$-catenin signaling regardless of $\beta$-catenin mutational status. Thus, the sorafenib/MEK inhibitor combination may represent an alternative treatment for patients with HCC whose tumors develop resistance to sorafenib therapy.

\section{Introduction}

Hepatocellular carcinoma (HCC) is the second most common cause of cancer mortality worldwide, and accounts for 500,000 to 1 million deaths annually worldwide (1). More than $80 \%$ of HCCs are discovered at a late stage when surgery is not an option (2). The 5-year-survival rate for resectable HCC ranges between 15 and 39\% (3), largely due to tumor recurrence. Two randomized controlled trials of sorafenib in patients with $\mathrm{HCC}$ demonstrated an improvement in median overall survival of $\sim 3$ months, and established sorafenib as a standard of care in advanced HCC $(4,5)$. Although sorafenib improves overall survival, the benefit is at best modest and confers a rather transient clinical benefit $(4,5)$. Recently, FDA has approved lenvatinib and regorafenib as first line and second line treatments, respectively, for HCC (6). Thus, effective novel therapies to combat this deadly disease are urgently required.

Aberrant activation of the $\mathrm{Wnt} / \beta$-catenin signaling pathway is found in up to $67 \%$ of $\mathrm{HCC}$ cases, underlining its importance in hepatocarcinogenesis (7). Tumors with nuclear and/or cellular accumulation of $\beta$-catenin had, generally, poorly differentiated morphology (8), high proliferative activity (9), high vascular invasion and a dismal prognosis (7-9). Gene expression studies have revealed distinct molecular subclasses in HCC, each associated with unique clinicopathological features. CTNNB1 ( $\beta$-catenin exon 3 mutated) class signature, which accounts for $20-30 \%$ of all $\mathrm{HCC}$ cases, a subset of $\mathrm{S} 3$, is enriched in hepatitis $\mathrm{C}$ virus (HCV)-related HCC and portends a better prognosis. Notably, the $\mathrm{S} 1$ subclass, which is characterized by non-mutated Wnt $/ \beta$-catenin activation signaling, is associated with non-HCV-related HCC, a larger tumor with moderately/poorly differentiated histology, propensity for vascular invasion 
and the development of satellite lesions, which is translated to early recurrence compared with other subclasses $(10,11)$. Several non-mutational mechanisms, including mutations in Axin 1 and Axin 2, have been put forward to explain the increased Wnt/ $\beta$-catenin signaling (12).

Besides cooperation with transforming growth factor- $\beta$, promoter methylation of secreted frizzled-related protein members and the overexpression of frizzled (FZD) receptors have been implicated (11). The accumulation of Wnt/FZD-signaling dysregulation was also revealed to be associated with increased activation of downstream effectors, $\beta$-catenin, protein kinase $\mathrm{C}$ and c-Jun $\mathrm{N}$-terminal kinase further implicating the importance of $\mathrm{Wnt} / \beta$-catenin signaling in hepatocarcinogenesis (13). These observations lend support to its functional relevance and therapeutic value.

Selumetinib (AZD6244; AstraZeneca, Cambridge, $\mathrm{UK})$ is an allosteric adenosine triphosphate-uncompetitive inhibitor of MEK1/2 (14). Refametinib (BAY 86-9766; Bayer $\mathrm{AG}$, Leverkusen, Germany) is a nonadenosine triphosphate competitive inhibitor targeting MEK 1/2 (15). Refametinib and selumetinib were selected for the present study as both have similar mechanisms in HCC. Although lack of activity was observed with selumetinib (14) and refametinib (16) monotherapies, they exhibited significant antitumor activity when combined with sorafenib in clinical trials $(16,17)$.

The aim of the present study was to investigate the effects of sorafenib and MEK inhibitor on tumor growth and the $\beta$-catenin signaling pathway in HCC.

\section{Materials and methods}

Reagents. Antibodies against disheveled segment polarity protein (DVL)2 (\#3224), DVL3 (\#3218), protein kinase B (AKT; \#9272), $\beta$-catenin (\#8480), Axin2 (\#5863), Cyclin D1 (\#2978), c-Myc (\#5605), c-Jun (\#9165), low-density lipoprotein receptor-related protein (LRP)6 (\#2560), survivin (\#2803), E-cadherin (\#3195), cleaved caspase 3 (\#9661), cleaved poly (ADP-ribose) polymerase (PARP; \#5625), and phosphorylation-specific antibodies against AKT Ser473 (\#9271), glycogen synthase kinase (GSK)-3 $\alpha \beta$ (Ser21/9; \#9331), RanBP3 Ser58 (\#9380), non-p (Active) $\beta$-catenin Ser33/Ser37/Thr41 (\#8814), phosphorylated (p)-histone 3 Ser10 (\#9701), LRP6 Ser1490 (\#2568), $\alpha$-tubulin (\#2144) and extracellular signal-regulated kinase (ERK)1/2 Thr202/Tyr204 (\#4370) were obtained from Cell Signaling Technology, Inc. (Danvers, MA, USA). The antibodies against ERK1/2 (sc-94), glutamine synthetase (SC-74430) were obtained from Santa Cruz Biotechnology, Inc. (Dallas, TX, USA). Anti-mouse cluster of differentiation (CD)31 antibody (\#102502) was from BioLegend, Inc. (San Diego, CA, USA). p- $\beta$-catenin Tyr142 (\#CP1081) was purchased from ECM Biosciences LLC (Versailles, KY, USA).

Conditioned medium. L-cells (ATCC CRL-2648) and L-Wnt-3A cells (ATCC CRL-2647) cells were obtained from the American Type Culture Collection (ATCC; Manassas, VA, USA). Control-conditioned medium from L-cells and Wnt-3A-conditioned medium from L-Wnt-3A cells was prepared according to the protocols provided by the
ATCC. The conditioned medium was concentrated $2 \mathrm{X}$ and sterile-filtered.

Cell culture. Between January 2004 and September 2018, 280 primary HCCs were obtained during surgery at Department of General Surgery, Singapore General Hospital (Singapore) and used for establishment of HCC PDX models. Written informed consent was obtained from all patients prior to tissue collection and the present study received Ethics Committee approval from National Cancer Centre Singapore (NCCS; Singapore) as well as Singapore General Hospital. HCC PDX models were established as described previously (18). Primary HCC13-0109, HCC26-0808A, and HCC06-0606 cells were freshly isolated from PDX tumors as follows: HCC tumors were finely minced and washed 3 times with modified Eagle's medium (MEM; Sigma-Aldrich; Merck KGaA, Darmstadt, Germany). The minced tissue was incubated with MEM containing 5\% fetal bovine serum (FBS; GE Healthcare Life Sciences, Logan, UT, USA) and $5 \mathrm{mg} / \mathrm{ml}$ collagenase (Roche Diagnostics, Indianapolis, IN, USA) at $37^{\circ} \mathrm{C}$ for $12 \mathrm{~h}$. Cells were harvested by centrifuging at $4^{\circ} \mathrm{C}$ at $800 \mathrm{x} \mathrm{g}$ for $10 \mathrm{~min}$. The cell pellets were washed 3 times with serum-free MEM, and primary HCC cells were plated at a density of $5.0 \times 10^{6}$ cells per well in MEM containing $10 \% \mathrm{FBS}$ and $1 \%$ penicillin-streptomycin (growth medium), and incubated at $37^{\circ} \mathrm{C}$ and $5 \% \mathrm{CO}_{2}$ for $48 \mathrm{~h}$. The primary cells were then used for subsequent experiments.

Primary HCC06-0606 or HCC07-0409 cells were treated with the vehicle, $0.5 \mu \mathrm{M}$ refametinib, $2.5 \mu \mathrm{M}$ sorafenib or $2.5 \mu \mathrm{M}$ sorafenib plus $0.5 \mu \mathrm{M}$ refametinib in growth medium at $37^{\circ} \mathrm{C}$ for $24 \mathrm{~h}$ then stimulated with concentrated conditioned medium prepared either from the control L-cells or L-Wnt-3A cells at $37^{\circ} \mathrm{C}$ for $2 \mathrm{~h}$. The cells were harvested, and changes in the levels of proteins of interest were determined by western blotting.

Antisense $\beta$-catenin transfection. Phosphorothioate oligonucleotides (ODN) directed against $\beta$-catenin antisense (5'-TAAGAGCTTAACCACAACTG-3') and scrambled control (5'-CAGTAATCGAATAGCTACCA-3') were purchased from TriLink Biotechnologies (San Diego, CA, USA). A further $5 \times 10^{6}$ HCC06-0606 cells were transfected with $150 \mathrm{nM}$ scrambled control or $150 \mathrm{nM}$ ODN directed against $\beta$-catenin using Plus ${ }^{\mathrm{TM}}$ Reagent (Invitrogen; Thermo Fisher Scientific, Inc., Waltham, MA, USA) at $37^{\circ} \mathrm{C}$ for $48 \mathrm{~h}$. The cells were subsequently assayed for $\beta$-catenin protein and its downstream targets by western blotting.

Combined treatment with sorafenib plus MEK inhibitor (refametinib or selumetinib). The present study was approved by the Ethics Board at NCCS (Singapore). Mice were maintained at NCCS according to the 'Guide for the Care and Use of Laboratory Animals' (19). All animal experiments were performed at NCCS.

Sorafenib (Nexavar ${ }^{\mathrm{TM}}$; Bayer AG) and selumetinib (14) (Selleck Chemicals, Houston, TX, USA) were suspended in vehicle [30\% captisol in water: $5 \%$ glucose (50\% v:v)] at 1.25 and $3.125 \mathrm{mg} / \mathrm{ml}$, respectively. Refametinib (Bayer AG) (15) was diluted in dimethyl sulfoxide at a concentration of $100 \mathrm{mg} / \mathrm{ml}$ as stock. Stock refametinib $(0.150 \mathrm{ml})$ was 
further diluted in $3.925 \mathrm{ml} \mathrm{30 \%} \mathrm{captisol} \mathrm{in} \mathrm{water} \mathrm{followed} \mathrm{by}$ $3.925 \mathrm{ml} \mathrm{5 \%}$ glucose to obtain an appropriate concentration.

Establishment of HCC patient-derived xenograft (PDX) model. Primary HCCs have previously been used to establish HCC PDX xenograft lines (18), of which the following 9 HCC lines (HCC01-0207; HCC25-0705A; HCC10-0505; HCC09-0913; HCC01-0708; HCC29-0909A; HCC06-0606; HCC26-0808A, and HCC07-0409), as well as one sorafenib-resistant HCC26-0808ASora54, were used to establish tumors in 450 male C.B-17 SCID mice aged 9-10 weeks and weighed 23-25 g (InVivos Pte. Ltd., Singapore) as described previously $(18,20)$. Mice were provided with sterilized food and water ad libitum, and housed in negative pressure isolators, which were set at $23^{\circ} \mathrm{C}$ and $43 \%$ humidity, with 12-h light/dark cycles.

Development of a sorafenib-resistant HCC model. C.B-17 SCID mice bearing HCC26-0808A tumors (18) were treated once daily with $10 \mathrm{mg} / \mathrm{kg}$ sorafenib for 80 to 90 days. Following the initial response to sorafenib, HCC26-0808A mice gradually acquired resistance, leading to further tumor growth. Sorafenib-resistant tumors were harvested for serial transplantation when they reached the size of $1,500 \mathrm{~mm}^{3}$. The cycle was repeated until sorafenib had minimal impact on the growth of treated tumors.

Mice bearing the indicated tumors (8-10 mice per group) were orally administered either $200 \mu \mathrm{l}$ vehicle, $10 \mathrm{mg} / \mathrm{kg}$ sorafenib, $15 \mathrm{mg} / \mathrm{kg}$ refametinib (or $25 \mathrm{mg} / \mathrm{kg}$ selumetinib) or $10 \mathrm{mg} / \mathrm{kg}$ sorafenib plus refametinib daily for 12-14 days. Treatment commenced when the tumors reached $150-175 \mathrm{~mm}^{3}$ in size. Bi-dimensional measurements were performed once every 2-3 days and tumor volumes were calculated based on the following formula: Tumor volume $=\left[(\right.$ length $) \times\left(\right.$ width $\left.\left.^{2}\right) \times(\pi / 6)\right]$, and plotted as the means \pm standard error of the mean for each treatment group vs. time, as previously described (18). Body and tumor weights were recorded at the time of sacrifice. The tumors were harvested $2 \mathrm{~h}$ following the final treatment and stored at $-80^{\circ} \mathrm{C}$ for later biochemical analysis. The efficacy of each treatment was determined using the $\mathrm{T} / \mathrm{C}$ ratio, where $\mathrm{T}$ and $\mathrm{C}$ are the median weight of drug-treated and vehicle-treated tumors, respectively, at the end of treatment.

Western blot analysis. Tumors from vehicle- and drug-treated mice were homogenized in buffer containing $50 \mathrm{mM}$ Tris- $\mathrm{HCl}$ pH 7.4, 150 mM NaCl, 0.5\% NP-40, 1 mM EDTA, 25 mM NaF, supplemented with proteinase inhibitors and $10 \mathrm{mM} \mathrm{Na} \mathrm{VO}_{4}$. Protein concentration was determined by Bradford assay. In total, $80 \mu \mathrm{g}$ protein/lane was resolved by either $8 \%$ or $14 \%$ SDS-PAGE, and western blotting was performed as previously described (21). All primary antibodies were diluted in $1 \%$ low-fat skimmed milk powder dissolved at a ratio of 1:1,000 to a final concentration of $1 \mu \mathrm{g} / \mathrm{ml}$. Blots were incubated with primary antibodies for $14-16 \mathrm{~h}$ at $4^{\circ} \mathrm{C}$. After 3 washes in TBST, blots were incubated with a secondary antibody [horseradish peroxidase (HRP)-conjugated goat anti-rabbit immunoglobulin (Ig)G (H+L; \#31460; 1:5,000; Thermo Fisher Scientific, Inc.] for $60 \mathrm{~min}$ at room temperature. All primary antibodies were then visualized using WesternBight ${ }^{\mathrm{TM}}$ ECL chemiluminescent detection reagents (Advansta, Inc., Menlo Park, CA, USA). For quantification analysis, total density of the band corresponding to protein blotting with the indicated antibody was quantified using the GS-900 Calibrated Densitometer and Image Lab ${ }^{\mathrm{TM}}$ Software 6.0.1 (Bio-Rad Laboratories, Inc., Hercules, CA, USA), normalized to both the tubulin loading control and the appropriate phosphorylated/total protein where applicable, and expressed as the fold-change.

Immunohistochemistry. Tumor tissues were fixed in PBS buffer containing 4\% formaldehyde (ICM Pharma, Pte. Ltd, Singapore) for $24 \mathrm{~h}$ at room temperature and embedded in paraffin. Tissue sections $(5-\mu \mathrm{m})$ were blocked with $5 \%$ low-fat skimmed milk powder dissolved in TBS containing $0.1 \%$ Tween (TBST) for $1 \mathrm{~h}$ at room temperature, followed by 3 washes in TBS. Sections were then incubated with CD31 (1:100), p-histone 3 Ser10 (1:300), cleaved PARP (1:100), and total $\beta$-catenin (1:150) antibodies for $14-16 \mathrm{~h}$ at $4^{\circ} \mathrm{C}$ to assess micro-vessel density, cell proliferation, and apoptosis, cytoplasmic and nuclear $\beta$-catenin, respectively, as described (20). Following 3 washes in TBST (5 min each), sections were incubated with biotin-conjugated goat anti-rabbit IgG secondary antibody (\#31820; 1:150; Thermo Fisher Scientific, Inc.) for $45 \mathrm{~min}$ at room temperature, followed by 3 washes in TBS and then incubated with streptavidin HRP-conjugated antibody (\#21126; 1:500; Thermo Fisher Scientific, Inc.). Slides were counterstained with hematoxylin (Sigma Diagnostics, Inc., Livonia, MI, USA) for $10 \mathrm{sec}$ at room temperature. Images were captured on an Olympus BX60 light microscope (Olympus Corporation, Tokyo, Japan). Five random $0.159-\mathrm{mm}^{2}$ fields at $\mathrm{x} 100$ magnification were captured for each tumor. The number of p-histone 3 Ser10 and cleaved PARP-positive cells among at least 500 cells per field was counted and expressed as the number of positive cells per 1,000 cells. For the quantification of mean microvessel density in sections stained for CD31, 5 random fields at a magnification of $\mathrm{x} 100$ were selected for each tumor.

Whole exome sequencing (WES). The CTNNB1 ( $\beta$-catenin) mutational status of 9 HCC models was determined via WES as described previously (22).

Statistical analysis. Data were presented as the mean \pm standard error of the mean. Differences in the protein level, tumor weight at sacrifice, p-histone 3 Ser10 index, mean micro-vessel density, and the number of cleaved PARP-positive cells were compared. Student's t-test was used for comparisons between two groups. One-way analysis of variance followed by the Tukey-Kramer method post-hoc test was used when comparing more than two groups. $\mathrm{P}<0.05$ was considered to indicate a statistically significant difference.

\section{Results}

Sorafenib/refametinib treatment inhibits tumor growth independent of $\beta$-catenin mutational status. WES analysis revealed that HCC29-0909A harbored a T41A $\beta$-catenin mutation, Y126 p53 mutation and EZH2 intergenic deletion; HCC10-0505 harbored a S45P $\beta$-catenin mutation, p53 deletion, and 2108G $>$ T JAK1 mutation. HCC01-0708 harbored a T41A $\beta$-catenin mutation, Y126 p53 mutation, and N-RAS amplification; HCC07-0409 harbored a T41A 


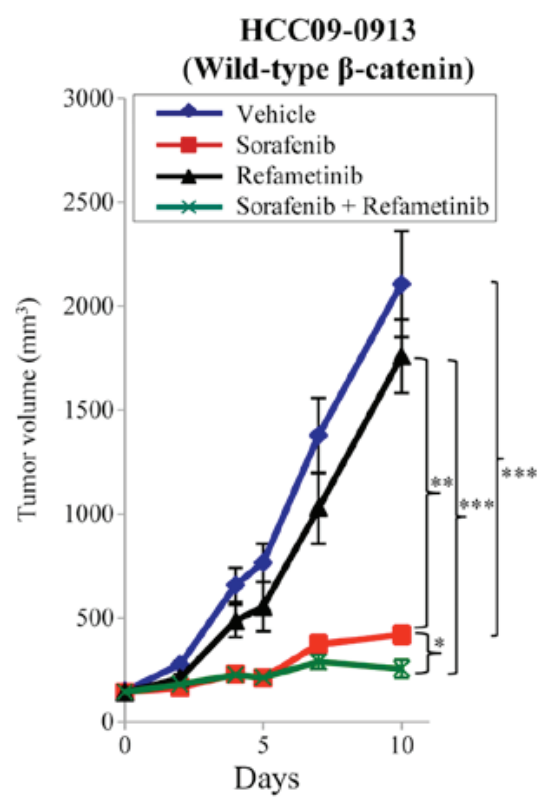

HCC26-0808A (Wild-type $\beta$-catenin)

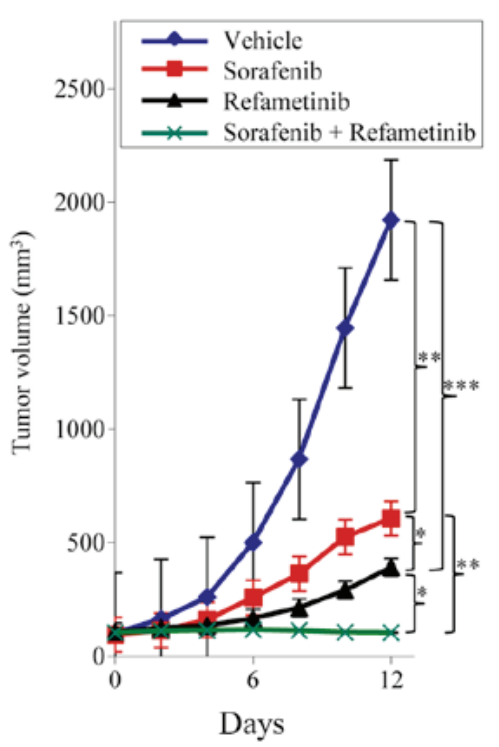

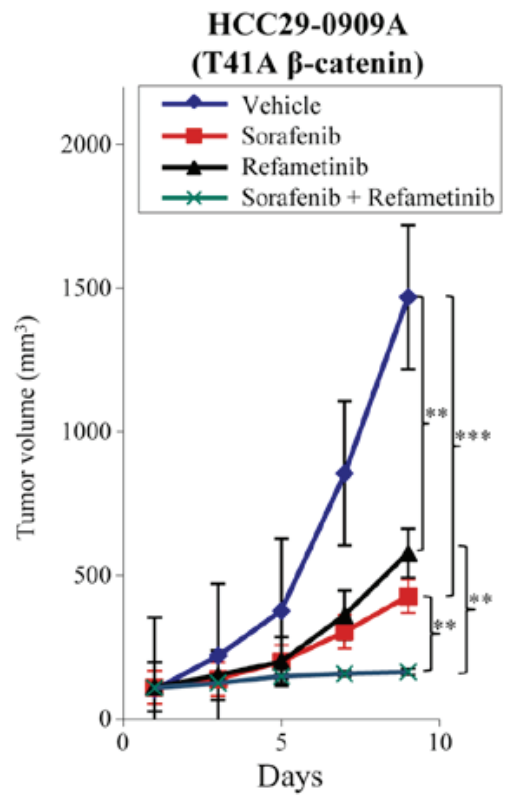

HCC06-0606 (Wild-type $\beta$-catenin)

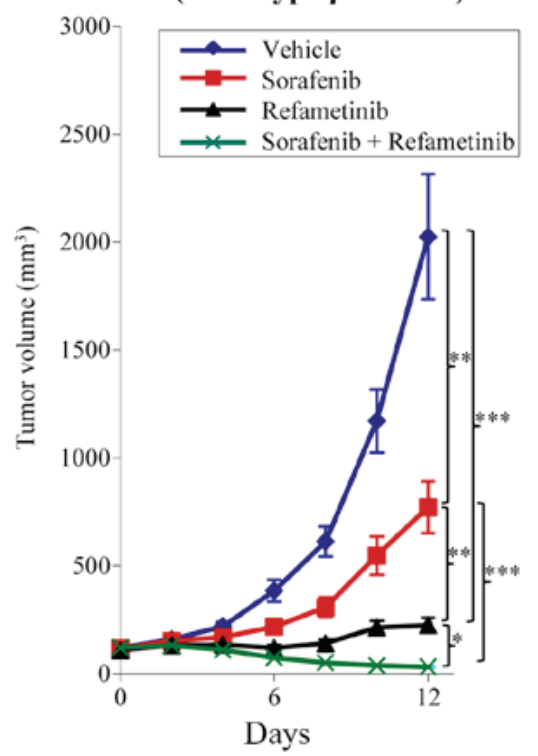

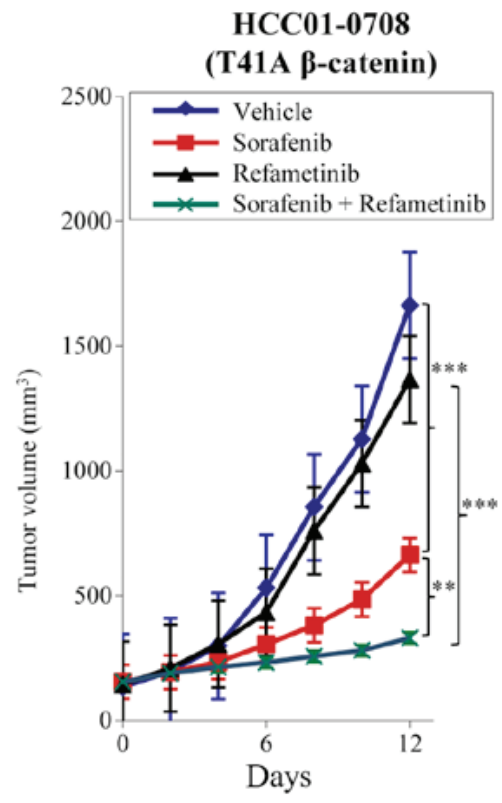

HCC01-0207

(Wild-type $\beta$-catenin)

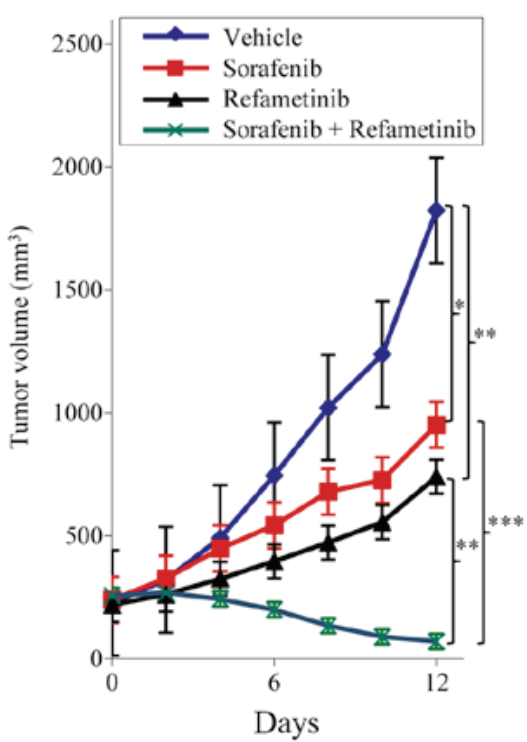

Figure 1. Effects of sorafenib, refametinib and sorafenib plus refametinib on tumor growth in wild-type and mutant $\beta$-catenin hepatocellular carcinoma models. Mice bearing the indicated tumors were orally administered $200 \mu \mathrm{l}$ vehicle, $10 \mathrm{mg} / \mathrm{kg}$ sorafenib, $15 \mathrm{mg} / \mathrm{kg}$ refametinib or sorafenib plus refametinib for the indicated number of days. Sorafenib and refametinib were given once daily. Each treatment arm comprised 8-10 independent tumor-bearing mice. Tumor volumes were calculated and plotted as the means \pm standard error of the means. One-way analysis of variance followed by the Tukey-Kramer method post-hoc test was used to establish significant differences among groups. ${ }^{*} \mathrm{P}<0.05,{ }^{* * *} \mathrm{P}<0.01$ and ${ }^{* * * *} \mathrm{P}<0.001$.

$\beta$-catenin mutation, Y126 p53 mutation, and CCND1 and N-RAS amplification; HCC26-0808A had a NF1 deletion, H168R p53 mutation, 3G>T VHL mutation, and loss of CDKN2A and CDKN2B; HCC06-0606 harbored a 407A>C p53 mutation and a MCL1 amplification; HCC01-0207 had a 341G >A RET mutation, R249S p53 mutation and LRP1B truncation; HCC25-0705A had a 341G $>$ A RET mutation and R249S p53 mutation; HCC09-0913 harbored a R249S p53 mutation. HCC01-0708, HCC07-0409 and HCC29-0909A harbored a T41A $\beta$-catenin mutation, and HCC10-0505 had S45P $\beta$-catenin mutations. These observations are consistent with those of previous studies, indicating that mutations in the $\beta$-catenin gene account for $20-30 \%$ of all HCC cases $(10,11)$.
As treatment with sorafenib led to the upregulation of p-ERK1/2 (21) and ERK kinase activated Wnt/ $\beta$-catenin signaling (23), the combined effects of sorafenib/MEK inhibitor on tumor growth and the Wnt/ $\beta$-catenin signaling pathway were evaluated. Consistent with our previous study (21), oral delivery of sorafenib led to significant inhibition of tumor growth as compared with the vehicle group $(\mathrm{P}<0.01)$. Addition of refametinib to sorafenib resulted in significantly improved anti-tumor activity in all HCC models tested when compared with either agent alone $(\mathrm{P}<0.01$; Fig. 1). As compared with the vehicle group, refametinib significantly inhibited tumor growth of HCC29-0909A, HCC26-0808A, HCC06-0606 and HCC01-0207 (P<0.01; Fig. 1) but not HCC09-0913 and 

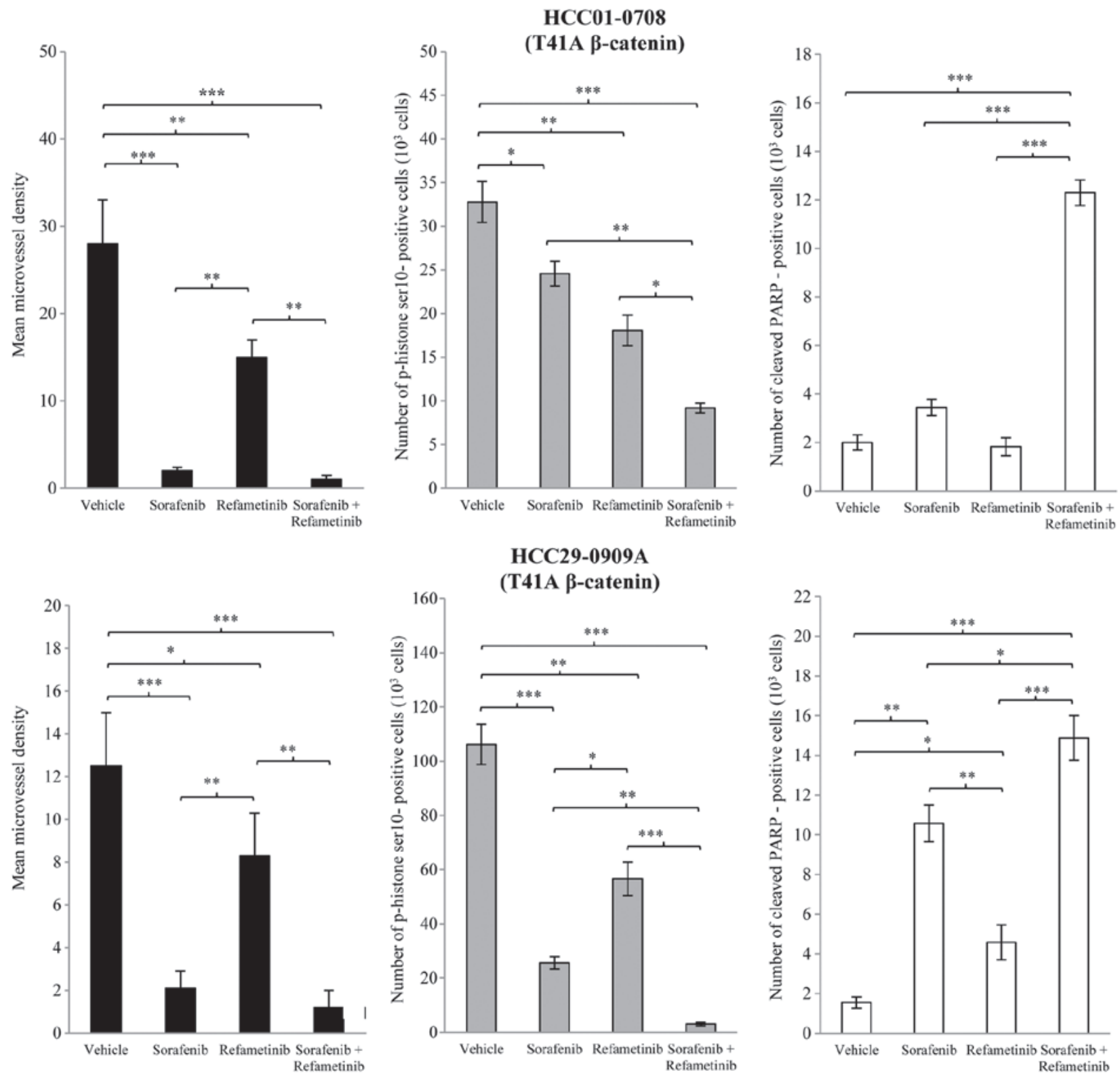

Figure 2. Effects of sorafenib/refametinib on angiogenesis, cell proliferation and apoptosis in T41 A mutant $\beta$-catenin HCC01-0708 and HCC29-0909A models. Mice bearing the indicated tumors were treated with $200 \mu \mathrm{l}$ vehicle, $10 \mathrm{mg} / \mathrm{kg}$ sorafenib, $15 \mathrm{mg} / \mathrm{kg}$ refametinib or sorafenib/refametinib for $10-15$ days. Sorafenib and refametinib were given once daily. Tumor tissues were collected $2 \mathrm{~h}$ following the final treatment. Each treatment arm comprised 8 independent tumor-bearing mice. Sections $(5-\mu \mathrm{m})$ were immunostained with cluster of differentiation 31, p-histone 3 Ser10 and cleaved PARP antibodies to assess microvessel density, cell proliferation and apoptosis, respectively. The number of p-histone 3 Ser10 and cleaved PARP-positive cells, among at least 500 cells counted per region, was determined and plotted as the mean number of positive cells per 1,000 cells \pm SE. For the quantification of the mean microvessel density \pm SE in each section, 5 random $0.159 \mathrm{~mm}^{2}$ fields at a magnification of $\mathrm{x} 100$ were observed for each tumor. Images were captured via light microscopy. Differences in mean microvessel density, p-histone 3 Ser10 and cleaved PARP-positive cells were compared using one-way analysis of variance followed by the Tukey-Kramer method post-hoc test. ${ }^{*} \mathrm{P}<0.05,{ }^{* *} \mathrm{P}<0.01$ and ${ }^{* * *} \mathrm{P}<0.001$. p, phosphorylated; PARP, poly (ADP-ribose) polymerase; SE, standard error of the mean.

HCC01-0708. Tumor regression was observed in wild-type $\beta$-catenin HCC26-0808A, HCC06-0606, HCC01-0207 and HCC09-0913 models following sorafenib/refametinib treatment. The antitumor activity of sorafenib/refametinib was independent of $\beta$-catenin mutational status as both mutant and wild-type $\beta$-catenin xenografts were inhibited by this combination (Fig. 1). Refametinib monotherapy was not considered to be active in HCC01-0708 (mutant $\beta$-catenin) and HCC09-0913 (wild-type $\beta$-catenin) models (Fig. 1), suggesting that factors other than $\beta$-catenin were responsible for the responsiveness. As predicted, sorafenib/refametinib inhibited cell proliferation and caused increased apoptosis, as compared with sorafenib or refametinib alone ( $\mathrm{P}<0.05$; Fig. 2). Similar results were obtained when selumetinib was combined with sorafenib (data not shown).

Sorafenib/refametinib combination treatment suppresses the $\beta$-catenin signaling pathway independent of its mutational status. The effects of sorafenib/refametinib combination on $\beta$-catenin and its downstream targets in mutant $\beta$-catenin HCC29-0909A and wild-type $\beta$-catenin HCC06-0606 xenografts were then investigated. As presented in Fig. 3, sorafenib alone had minimal effect on p-LRP6 Ser1490 
A

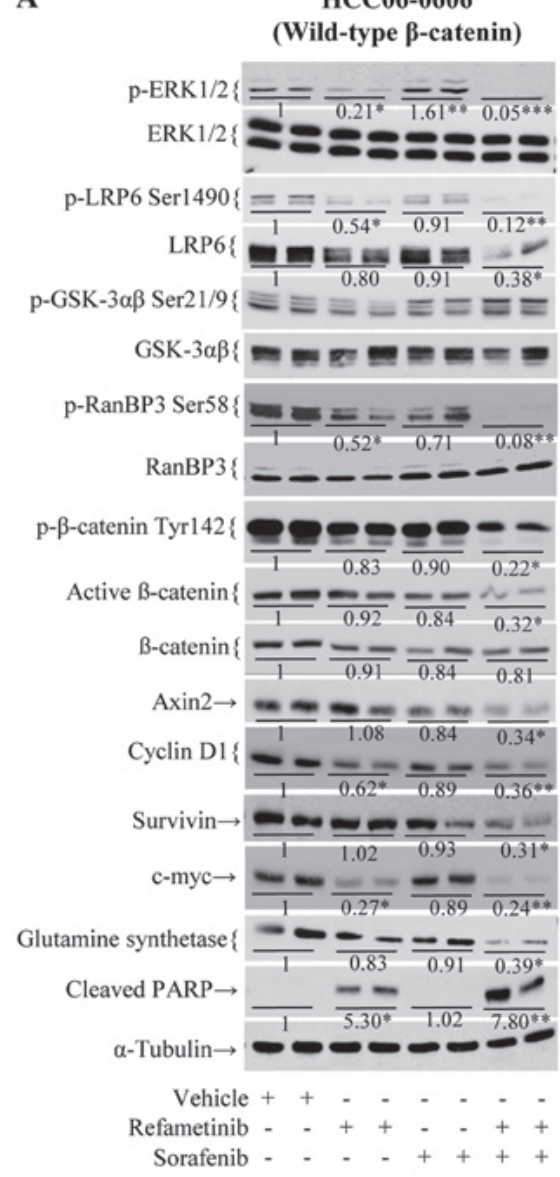

B

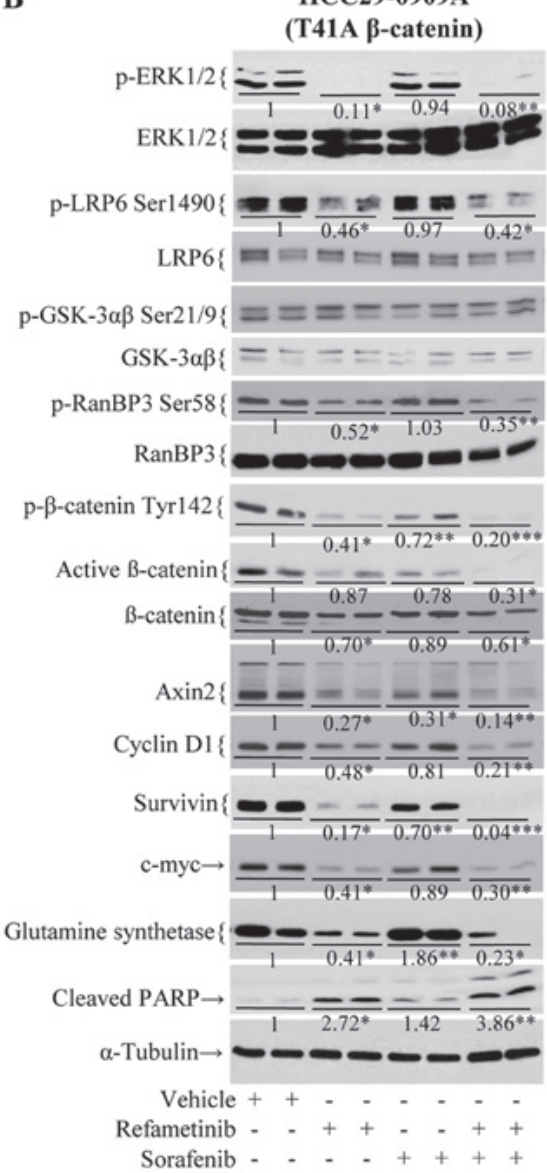

Figure 3. Effects of sorafenib/refametinib on Wnt/ $\beta$-catenin signaling in (A) wild-type $\beta$-catenin HCC06-0606 (B) and T41A mutant $\beta$-catenin HCC29-0909A models. Mice bearing the indicated tumors were treated with $200 \mu \mathrm{l}$ vehicle, $10 \mathrm{mg} / \mathrm{kg}$ sorafenib, $15 \mathrm{mg} / \mathrm{kg}$ refametinib and sorafenib/refametinib once daily for 5 days. Each treatment arm comprised 3-4 independent tumor-bearing mice. Tumors were collected $2 \mathrm{~h}$ following the final dose for marker analysis. Tumor lysates were analyzed by western blotting. Blot membranes were incubated with the indicated antibodies. Representative blots are presented. Total density of the band corresponding to protein blotting with the indicated antibody was quantified, normalized to both the tubulin loading control and the phosphorylated/total protein (e.g., ERK and LRP6) and expressed as the fold-change. ${ }^{*} \mathrm{P}<0.05,{ }^{* * *} \mathrm{P}<0.01$ and ${ }^{* * *} \mathrm{P}<0.001$ vs. vehicle. p, phosphorylated; ERK, extracellular signal-regulated kinase; LRP, low-density lipoprotein receptor-related protein 6; GSK, glycogen synthetase kinase; PARP, poly (ADP-ribose) polymerase.

and p-RanBP3 Ser58. Quantification of the immunoblots revealed that a decrease in these proteins was observed in refametinib-treatedHCC06-0606(Fig.3A) and HCC29-0909A xenografts (Fig. 3B). Notably, sorafenib/refametinib resulted in a significant decrease in p-LRP6 Ser1490 (P<0.05; Fig. 3). As presented in Fig. 3, there was no significant difference in $\mathrm{p}-\mathrm{GSK}-3 \alpha \beta$ (Ser21/9) levels between the treatment groups. Although total $\beta$-catenin was modestly reduced, p- $\beta$-catenin Tyr142, p-RanBP-3 Ser58 and active $\beta$-catenin in sorafenib/refametinib-treated tumors were significantly reduced $(\mathrm{P}<0.05$; Fig. 3). Significant reduction of $\beta$-catenin downstream targets (Axin-2, survivin, c-Myc, cyclin D1 and glutamine synthetase) in sorafenib/refametinib-treated tumors was observed $(\mathrm{P}<0.05$; Fig. 3$)$. Similar results were observed when wild-type HCC09-0913 and mutant $\beta$-catenin HCC01-0708 were treated with sorafenib/selumetinib (data not shown).

Sorafenib/refametinib combination treatment causes export of $\beta$-catenin to the membrane. The tyrosine kinases have been demonstrated to induce phosphorylation of $\beta$-catenin at tyrosine $142(24,25)$. As $p$ - $\beta$-catenin Tyr142 (24) and p-RanBP3 (26) have been reported to be involved in $\beta$-catenin export, whether sorafenib/refametinib treatment caused nuclear export was examined. Tumor sections among different treatment groups were stained with total $\beta$-catenin antibody. Intense nuclear and cytoplasmic $\beta$-catenin staining was observed in vehicle-treated mutant $\beta$-catenin tumors (HCC29-0909A and HCC01-0708) (Fig. 4). The majority of $\beta$-catenin in sorafenib-treated tumors was located in the cytoplasm and nucleus (Fig. 4). Refametinib markedly reduced nuclear and cytoplasmic $\beta$-catenin concomitant with a marked increase in membranous $\beta$-catenin (Fig. 4). There was no clear difference in $\beta$-catenin relocalization between sorafenib- and refametinib-treated tumors. Notably, nuclear $\beta$-catenin staining was barely detectable in HCC29-0909A and HCC01-0708 tumors treated with sorafenib/refametinib (Fig. 4). The nuclear staining was less pronounced in the HCC10-0505 model with the S45P mutant of $\beta$-catenin, suggesting that there may be functional differences amongst the various mutations (data not shown). In HCC29-0909A and HCC01-0708 models, a membranous signal accumulated in areas of intercellular contact, likely representing $\beta$-catenin associated with membranous cadherins $(24,27)$. These observations suggest that $\beta$-catenin export from the nucleus and/or the cytoplasm to the membrane following sorafenib/refametinib treatment likely occurs via 


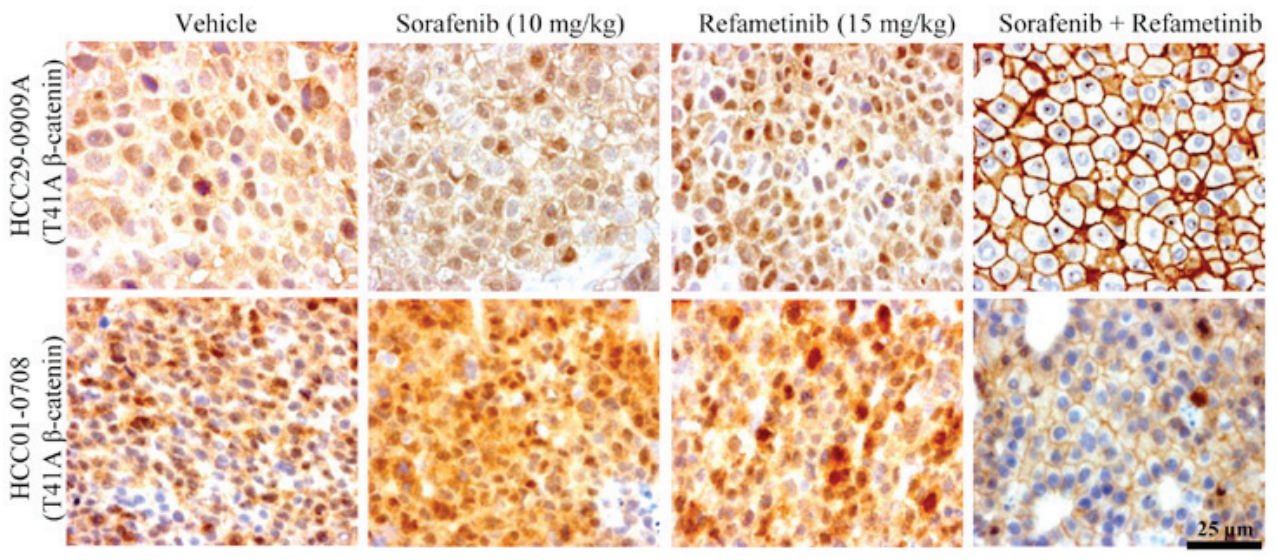

Figure 4. Membrane localization of $\beta$-catenin following sorafenib/refametinib treatment in T41A mutant $\beta$-catenin HCC29-0909A and T41A mutant $\beta$-catenin HCC01-0708 patient-derived xenograft models. Mice bearing the indicated tumors were treated with $200 \mu \mathrm{l}$ vehicle, $10 \mathrm{mg} / \mathrm{kg}$ sorafenib, $15 \mathrm{mg} / \mathrm{kg}$ refametinib or sorafenib/refametinib for 10-12 days. Each treatment arm comprised 8-10 independent tumor-bearing mice. Tumor tissue samples were collected $2 \mathrm{~h}$ following the last dose and paraffin-embedded. Sections $(5-\mu \mathrm{m})$ were immunostained with total $\beta$-catenin antibody to assess cytoplasmic, membranous and nuclear $\beta$-catenin. Representative images of tumor sections from vehicle- and drug-treated tumors stained for $\beta$-catenin are presented. Scale bar, $25 \mu \mathrm{m}$.

A

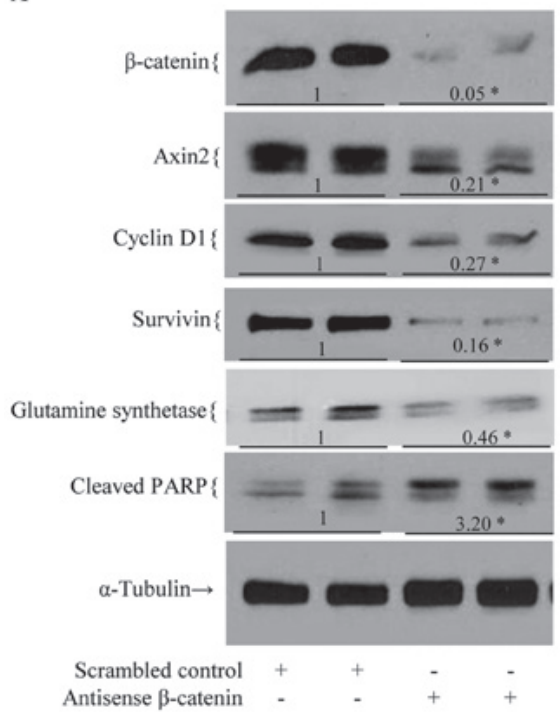

B

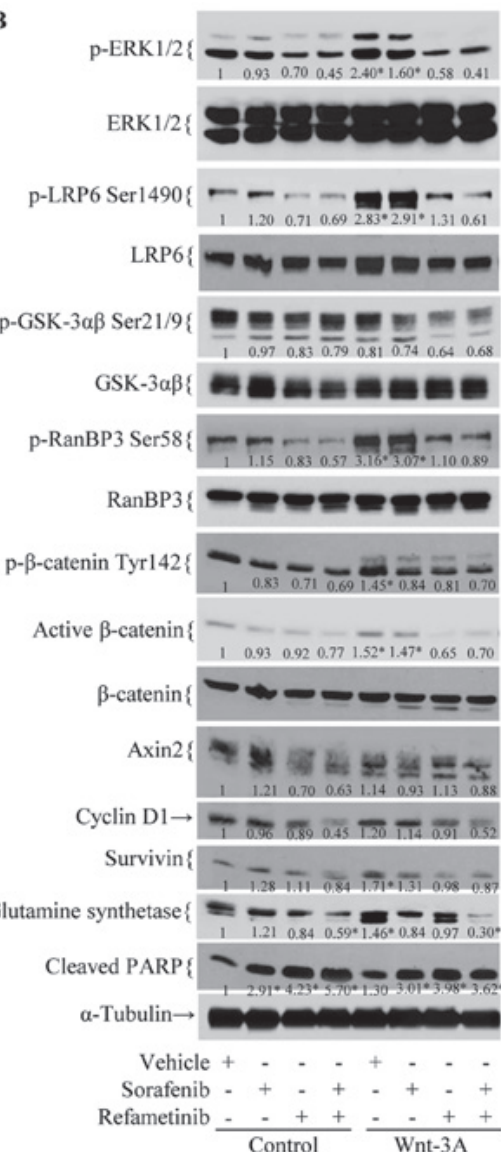

Figure 5. Effect of antisense $\beta$-catenin on $\beta$-catenin signaling, and the effect of sorafenib/refametinib on Wnt-3A-stimulated activation of Wnt/ $\beta$-catenin signaling in wild-type $\beta$-catenin HCC06-0606 cells. (A) Primary HCC06-0606 cells were transfected with scrambled control or antisense $\beta$-catenin for $48 \mathrm{~h}$. The cells were subsequently assayed for $\beta$-catenin protein and its downstream targets by western blotting. ${ }^{*} \mathrm{P}<0.05$ vs. scrambled control. (B) Primary HCC06-0606 cells were treated with $1 \mu \mathrm{l}$ of vehicle, $0.5 \mu \mathrm{M}$ refametinib, $2.5 \mu \mathrm{M}$ sorafenib or $2.5 \mu \mathrm{M}$ sorafenib plus $0.5 \mu \mathrm{M}$ refametinib in modified Eagle's medium containing $2 \%$ fetal bovine serum for $24 \mathrm{~h}$ then stimulated with concentrated conditioned medium prepared either from the control L-cells or L-Wnt-3A cells for $2 \mathrm{~h}$. Western blot analysis was performed. Representative blots are presented. Quantification of proteins involved in the $\beta$-catenin-signaling pathway was performed. "P<0.05 vs. vehicle control. PARP, poly (ADP-ribose) polymerase; p, phosphorylated; ERK, extracellular signal-regulated kinase; LRP6, low-density lipoprotein receptor-related protein 6; GSK, glycogen synthase kinase.

the inhibition of p- $\beta$-catenin Tyr142 (25) and p-RanBP3 (26). $\beta$-catenin relocalization also occurred when HCC09-0913 tumors were treated with sorafenib/selumetinib (data not shown).
Sorafenib/refametinib inhibits Wnt-3A-induced activation of the $\beta$-catenin signaling pathway. As presented in Fig. $5 \mathrm{~A}$, treatment with antisense, but not scrambled control, $\beta$-catenin 

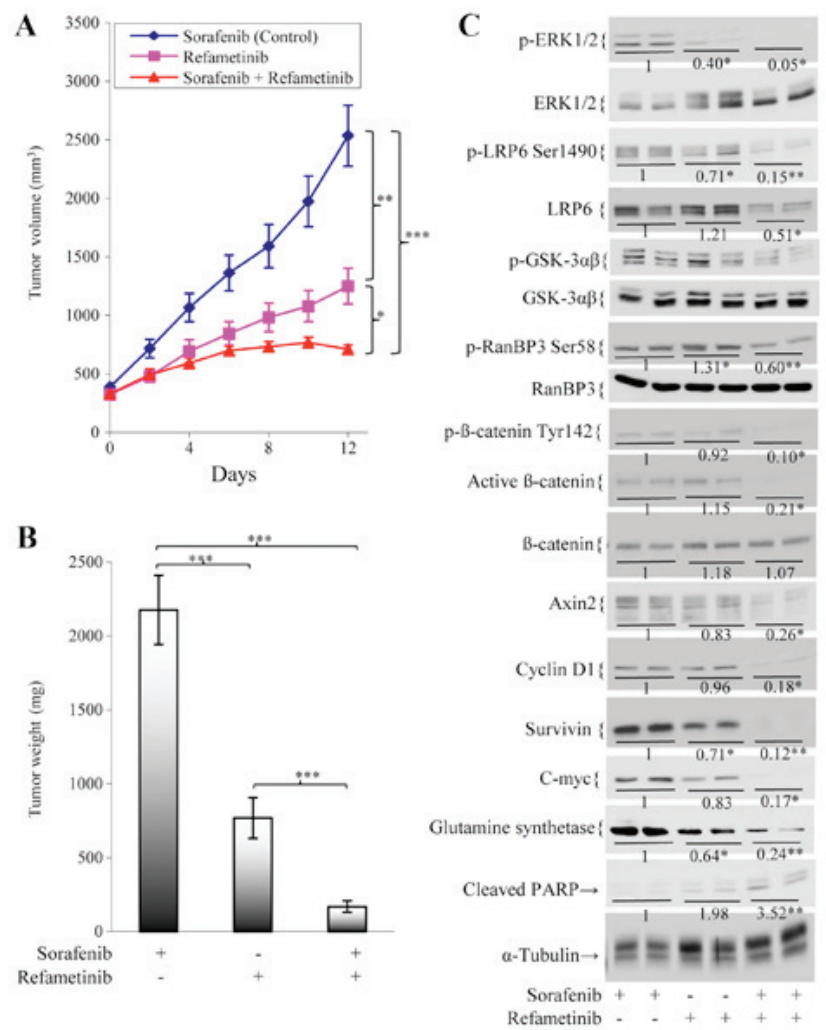

D

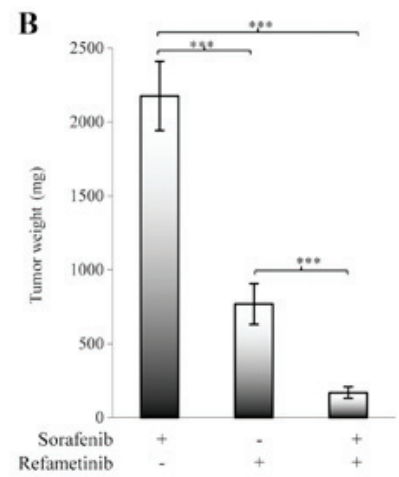

Figure 6. Effects of sorafenib/refametinib on tumor growth and the $\beta$-catenin-signaling pathway in sorafenib-resistant HCC26-0808ASora54 xenografts. Mice bearing HCC26-0808ASora54 tumors were treated with $10 \mathrm{mg} / \mathrm{kg}$ sorafenib (control treatment), $15 \mathrm{mg} / \mathrm{kg}$ refametinib or sorafenib/refametinib once daily for 12 days. Each treatment arm comprised 10 independent tumor-bearing mice. Treatments began when the tumors reached $\sim 350 \mathrm{~mm}^{3}$ in size. (A) Tumor volumes at given time points and (B) the corresponding tumor weights are presented. Data are presented as the mean \pm standard error of the mean. One-way analysis of variance followed by the Tukey-Kramer method post-hoc test was used to establish significant differences among groups. ${ }^{*} \mathrm{P}<0.05,{ }^{* * *} \mathrm{P}<0.01$ and ${ }^{* * * *} \mathrm{P}<0.001$. (C) Western blot analysis of $\beta$-catenin signaling pathway proteins and quantification of proteins involved in the $\beta$-catenin-signaling pathway are presented. ${ }^{*} \mathrm{P}<0.05$ and ${ }^{* *} \mathrm{P}<0.01$ vs. sorafenib. (D) Representative pictures of $\beta$-catenin stained with an anti- $\beta$-catenin antibody are presented. Scale bars, $25 \mu \mathrm{m}$. $\mathrm{p}$ phosphorylated; ERK, extracellular signal-regulated kinase; LRP6, low-density lipoprotein receptor-related protein 6; GSK, glycogen synthase kinase; PARP, poly (ADP-ribose) polymerase.

resulted in decreased cell viability, $\beta$-catenin levels and those of its known downstream targets. Treatment of wild-type $\beta$-catenin HCC06-0606 cells with Wnt-3A-conditioned medium led to the significant upregulation of p-LRP6 Ser1490, p-ERK1/2 Thr202/Tyr204, p-RanBP3 Ser58 and p- $\beta$-catenin Tyr142 ( $\mathrm{P}<0.01$; Fig. 5B) as compared with control-conditioned medium. Marked increases in survivin, cyclin D1 and glutamine synthetase were also noted. Pre-treatment of HCC06-0606 cells with refametinib or sorafenib/refametinib, but not with sorafenib, for $24 \mathrm{~h}$ abolished Wnt-3A-induced upregulation of p-LRP6 Ser1490, p- $\beta$-catenin Tyr142, p-RanBP3 Ser58 and p-ERK1/2 Thr202/Tyr204 ( $\mathrm{P}<0.05$; Fig. 5B). These findings suggest that sorafenib/refametinib profoundly suppressed $\beta$-catenin activity, resulting in decreased proliferation and elevated levels of apoptosis. Similar observations were obtained when mutant $\beta$-catenin HCC07-0409 cells were treated with Wnt-3A-conditioned medium (data not shown).

Sorafenib/refametinib treatment has anti-tumor effects in a sorafenib-resistant HCC model. While growth of the parental HCC26-0808A line was significantly reduced by sorafenib, growth of the HCC26-0808ASora54 line was unaffected (data not shown). This indicates that HCC26-0808ASora54 is resistant to sorafenib treatment. As presented in Fig. 6A, sorafenib-resistant HCC26-0808ASora54 tumors that continued to grow in the presence of sorafenib experienced a significant reduction in tumor growth when ERK activity was blocked by refametinib $(\mathrm{P}<0.001)$. The addition of refametinib to sorafenib abolished tumor growth (Fig. 6A) and the final tumor weight of sorafenib/refametinib group was significantly smaller than that of the refametinib or sorafenib groups $(\mathrm{P}<0.001$; Fig. 6B). This was associated with inhibition of the $\beta$-catenin signaling pathway, as evidenced by a significant reduction in p-LRP6 Ser1490, p- $\beta$-catenin Tyr142, p-RanBP-3 Ser58, and active non-phospho- $\beta$-catenin, Axin2, survivin, cyclin D1, c-Myc, and glutamine synthetase levels $(\mathrm{P}<0.05$; Fig. 6C). Nuclear exportation of $\beta$-catenin was also observed when HCC26-0808ASora54 was treated with sorafenib/refametinib (Fig. 6D).

\section{Discussion}

$\mathrm{HCC}$ is the second leading cause of cancer mortality worldwide, often presenting in the advanced stage when cure is no longer possible. Although sorafenib improves the overall survival of patients with HCC, the benefit is modest and treatment confers only a transient clinical benefit $(4,5)$. As such, there is an urgent need for more efficacious systemic therapies. Mutations affecting the Wnt/ $\beta$-catenin pathway have been found in $26-40 \%$ of HCC cases (28-30). Activation of the Wnt/ $\beta$-catenin 
pathway leads to upregulation of downstream target genes that regulate cell proliferation and tumor progression $(31,32)$. As such, agents targeting the Wnt/ $\beta$-catenin pathway may be an alternative therapy for patients with $\beta$-catenin-dependent tumors. Targeting Wnt/ $\beta$-catenin has been comprehensively discussed $(33,34)$. Wnt $/ \beta$-catenin pathway inhibitor ICG001, FH535 and other small inhibitors have been tested in HCC models (35-37). Combinations of sorafenib/ICG001 or sorafenib/FH535 had better treatment outcomes in their experimental models $(38,39)$. These studies have demonstrated that the promoted downregulation or degradation of wild-type $\beta$-catenin is the mechanism of $\beta$-catenin pathway inhibition in $\mathrm{HCC}$.

In the present study, combinations of sorafenib/refametinib or sorafenib/selumetinib inhibited cell proliferation and induced apoptosis, both of which were associated with the downregulation of p-ERK1/2, p-RanBP3 Ser58, p-LRP6 Ser1490, p- $\beta$-catenin Tyr142, and $\beta$-catenin target genes. In addition, the sorafenib/refametinib combination suppressed Wnt-3A-induced activation of the Wnt/ $\beta$-catenin signaling pathway in HCC cells. Although the overall levels of $\beta$-catenin were not significantly changed, those of non-p- (active) $\beta$-catenin in sorafenib/refametinib-treated tumors were significantly reduced. Whereas vehicle-treated and sorafenib-treated mutant $\beta$-catenin tumors exhibited strong cytoplasmic and nuclear $\beta$-catenin localization, the majority of the $\beta$-catenin in sorafenib/refametinib-treated tumors was accumulated at the membrane. The precise mechanisms by which sorafenib/refametinib or sorafenib/selumetinib inactivates the $\mathrm{Wnt} / \beta$-catenin pathway remain unclear. It is possible that sorafenib/refametinib or sorafenib/selumetinib inactivates the Wnt/ $\beta$-catenin pathways by inhibiting p- $\beta$-catenin Tyr142 (40) and p-RanBP3 Ser58 (26). This leads to a reduction in nuclear $\beta$-catenin and $\beta$-catenin-dependent transcription (40-43). As phosphorylation of $\beta$-catenin at tyrosine 142 is also essential for binding to E-cadherin $(41,43)$ and $\alpha$-catenin $(27,40,42,44)$, respectively, inhibition of $\mathrm{p}-\beta$-catenin Tyr142 by sorafenib/MEK inhibitor may facilitate the interaction of E-cadherin and $\alpha$-catenin with $\beta$-catenin at the membrane, leading to a decrease of the cytosolic pool without reducing total $\beta$-catenin levels (45). In the present study, suppressing $\beta$-catenin by sorafenib/refametinib reduces $\mathrm{p}$-histone 3 Ser10, cyclin B1, cyclin D1, c-Myc, and survivin protein expression, providing the link between $\beta$-catenin signaling pathway and cell cycle. In addition, sorafenib/refametinib also reduced glutamine synthetase, which in turn may deplete cellular glutamine. As activation of Wnt/ $\beta$-catenin is implicated in maintenance of tumor initiating cells, drug resistance, tumor progression and metastasis (31), it remains to be determined if sorafenib/refametinib inhibits the proliferation of liver cancer stem cells.

Sorafenib/refametinib or sorafenib/selumetinib targets wild-type as well as T41A- and S45P-mutated $\beta$-catenin, which have beenidentified in 2-18.8\% of analyzed HCC cases (7,46-50). These mutations were revealed to activate the $\beta$-catenin pathway by preventing GSK3-mediated phosphorylation at Ser33/37, further avoiding $\beta$-TrCP recognition (51-53). In the present study, it was observed that the levels of $\mathrm{p}-\mathrm{GSK}-3 \alpha \beta$ (Ser21/9) and total $\beta$-catenin were not significantly altered by sorafenib/refametinib or sorafenib/selumetinib treatment. It is unlikely that downregulation or degradation of $\beta$-catenin by GSK3 is the mechanism by which sorafenib/refametinib or sorafenib/selumetinib inhibits the $\beta$-catenin pathway. Enhanced nuclear $\beta$-catenin export due to the inhibition of p- $\beta$-catenin Tyr142 $(40,42)$ and p-RanBP3 Ser58 (26) may have a key role in sorafenib/MEK inhibitor mediated inactivation of $\beta$-catenin signaling pathway.

Treatment with sorafenib, although associated with inhibition of tumor growth and angiogenesis in in vivo studies, led to the upregulation of p-ERK1/2 (21), which is one of the most critical cellular signaling pathways supporting hepatocarcinogenesis. The addition of a MEK inhibitor (selumetinib or refametinib) to sorafenib resulted in the attenuation of p-ERK1/2 activity and greater antitumor effects $(17,21)$. In the present study, 'adaptive' tumor growth in the presence of sorafenib experienced a marked reduction when MEK/ERK activity was blocked. These findings suggest that resistance to sorafenib may be overcome by adding refametinib (or selumetinib) to sorafenib.

We recently reported that a phase Ib study of selumetinib (AZD6244) in combination with sorafenib in advanced HCC demonstrated encouraging anti-tumor activity with acceptable adverse events (17). In the SHARP trial, sorafenib monotherapy was associated with an median progression-free survival (mPFS) and median overall survival (mOS) of 5.5 and 10.7 months, respectively (5). A phase III study of sorafenib in patients in the Asia-Pacific region with advanced hepatocellular carcinoma reported an mPFS and mOS of 2.8 and 6.5 months, respectively (4). mPFS and mOS of 5.6 and 14.4 months, respectively, achieved with combination sorafenib and selumetinib is encouraging. Lack of activity observed with selumetinib monotherapy in a previous study suggests synergistic anti-tumor effect are possible with this combination (17). The robust anti-tumor activity of sorafenib/selumetinib presented in HCC PDX models and in phase $1 \mathrm{~b}$ clinical trial warrants the development of phase II clinical trials. In a phase $1 \mathrm{~b}$ study of selumetinib in combination with sorafenib in HCC, a high incidence of grade 3/4 diarrhea (44\%) and the finding that $66 \%$ of SAEs were GI-related (vomiting/diarrhea) are testament of overlapping toxicities between sorafenib and selumetinib (17). In the present study, dose reductions were required for sorafenib. Patient education and prompt aggressive management strategies may potentially mitigate some of the toxicities. A phase II study of refametinib and sorafenib also demonstrated these agents to be clinically active in patients with HCC and mutant KRAS tumors (16). These results also suggest that a therapy regimen involving the combination of sorafenib and a MEK inhibitor could possibly reverse sorafenib-resistance in patients with HCC.

\section{Acknowledgements}

The authors would like to thank Dr Dieter Zopf (Bayer AG, Leverkusen, Germany) for his critical reading of this manuscript.

\section{Funding}

The present study was supported by grants (NMRC/ MOHIAFCAT2/006/2016, NMRC/MOHIAFCat1/0042/2016, NMRC/MOHIAFCat1/0040/2016, NMRC/MOHIAFCat1/ 
0022/2015, NMRC/MOHIAFCat $1 / 0003 / 2014$, and NMRC/MOHIAFCat1/0004/2014) from National Medical Research Council. This project was supported in part by Bayer AG (Leverkusen, Germany).

\section{Availability of data and materials}

All data generated or analyzed during this study are available from the corresponding author on reasonable request.

\section{Authors' contributions}

$\mathrm{HH}, \mathrm{LL}$ and RO were responsible for collection and assembly of data. FP, AS, OP, DM, KZ and $\mathrm{HH}$ were responsible for financial support, provision of study materials and study design. $\mathrm{HH}$ and KG were responsible for data analysis, interpretation and writing the manuscript. All authors provided final approval of the article.

\section{Ethics approval and consent to participate}

Written informed consent was obtained from all patients prior to tissue collection. The present study was approved by the Ethics Board at National Cancer Centre Singapore (Singapore) and at Singapore General Hospital (Singapore). All mice were maintained according to the 'Guide for the Care and Use of Laboratory Animals'.

\section{Patient consent for publication}

Not applicable.

\section{Competing interests}

FP, AS, OP, DM and $\mathrm{KZ}$ are employees of Bayer AG (Leverkusen, Germany).

\section{References}

1. Siegel RL, Miller KD and Jemal A: Cancer Statistics, 2017. CA Cancer J Clin 67: 7-30, 2017.

2. Nagasue N, Kohno H, Chang YC, Taniura H, Yamanoi A, Uchida M, Kimoto T, Takemoto Y, Nakamura T and Yukaya H: Liver resection for hepatocellular carcinoma. Results of 229 consecutive patients during 11 years. Ann Surg 217: 375-384, 1993.

3. Takenaka K, Kawahara N, Yamamoto K, Kajiyama K, Maeda T, Itasaka H, Shirabe K, Nishizaki T, Yanaga K and Sugimachi K: Results of 280 liver resections for hepatocellular carcinoma. Arch Surg 131: 71-76, 1996

4. Cheng AL, Kang YK, Chen Z, Tsao CJ, Qin S, Kim JS, Luo R, Feng J, Ye S, Yang TS, et al: Efficacy and safety of sorafenib in patients in the Asia-Pacific region with advanced hepatocellular carcinoma: A phase III randomised, double-blind, placebo-controlled trial. Lancet Oncol 10: 25-34, 2009.

5. Llovet JM, Ricci S, Mazzaferro V, Hilgard P, Gane E, Blanc JF de Oliveira AC, Santoro A, Raoul JL, Forner A, et al; SHARP Investigators Study Group: Sorafenib in advanced hepatocellular carcinoma. N Engl J Med 359: 378-390, 2008.

6. Dawkins J and Webster RM: The hepatocellular carcinoma market. Nat Rev Drug Discov 18: 13-14, 2018.

7. Wong CM, Fan ST and Ng IO: beta-Catenin mutation and overexpression in hepatocellular carcinoma: Clinicopathologic and prognostic significance. Cancer 92: 136-145, 2001.

8. Endo K, Ueda T, Ueyama J, Ohta T and Terada T: Immunoreactive E-cadherin, alpha-catenin, beta-catenin, and gamma-catenin proteins in hepatocellular carcinoma: Relationships with tumor grade, clinicopathologic parameters, and patients' survival. Hum Pathol 31: 558-565, 2000.
9. Inagawa S, Itabashi M, Adachi S, Kawamoto T, Hori M, Shimazaki J, Yoshimi F and Fukao K: Expression and prognostic roles of beta-catenin in hepatocellular carcinoma: Correlation with tumor progression and postoperative survival. Clin Cancer Res 8: 450-456, 2002.

10. Hoshida Y, Nijman SM, Kobayashi M, Chan JA, Brunet JP, Chiang DY, Villanueva A, Newell P, Ikeda K, Hashimoto M, et al: Integrative transcriptome analysis reveals common molecular subclasses of human hepatocellular carcinoma. Cancer Res 69: 7385-7392, 2009.

11. Lachenmayer A, Alsinet C, Savic R, Cabellos L, Toffanin S, Hoshida Y, Villanueva A, Minguez B, Newell P, Tsai HW, et al: Wnt-pathway activation in two molecular classes of hepatocellular carcinoma and experimental modulation by sorafenib. Clin Cancer Res 18: 4997-5007, 2012.

12. Taniguchi K, Roberts LR, Aderca IN, Dong X, Qian C, Murphy LM, Nagorney DM, Burgart LJ, Roche PC, Smith DI, et al: Mutational spectrum of beta-catenin, AXIN1, and AXIN2 in hepatocellular carcinomas and hepatoblastomas. Oncogene 21: 4863-4871, 2002.

13. Bengochea A, de Souza MM, Lefrançois L, Le Roux E, Galy O, Chemin I, Kim M, Wands JR, Trepo C, Hainaut P, et al: Common dysregulation of Wnt/Frizzled receptor elements in human hepatocellular carcinoma. Br J Cancer 99: 143-150, 2008.

14. O'Neil BH, Goff LW, Kauh JS, Strosberg JR, Bekaii-Saab TS, Lee RM, Kazi A, Moore DT, Learoyd M, Lush RM, et al: Phase II study of the mitogen-activated protein kinase $1 / 2$ inhibitor selumetinib in patients with advanced hepatocellular carcinoma. J Clin Oncol 29: 2350-2356, 2011.

15. Iverson C, Larson G, Lai C, Yeh LT, Dadson C, Weingarten P, Appleby T, Vo T, Maderna A, Vernier JM, et al: RDEA119/BAY 869766: A potent, selective, allosteric inhibitor of MEK1/2 for the treatment of cancer. Cancer Res 69: 6839-6847, 2009.

16. Lim HY, Heo J, Choi HJ, Lin CY, Yoon JH, Hsu C, Rau KM, Poon RT, Yeo W, Park JW, et al: A phase II study of the efficacy and safety of the combination therapy of the MEK inhibitor refametinib (BAY 86-9766) plus sorafenib for Asian patients with unresectable hepatocellular carcinoma. Clin Cancer Res 20: 5976-5985, 2014.

17. Tai WM, Yong WP, Lim C, Low LS, Tham CK, Koh TS, Ng QS, Wang WW, Wang LZ, Hartano S, et al: A phase Ib study of selumetinib (AZD6244, ARRY-142886) in combination with sorafenib in advanced hepatocellular carcinoma (HCC). Ann Oncol 27: 2210-2215. 2016

18. Huynh H, Soo KC, Chow PK, Panasci L and Tran E: Xenografts of human hepatocellular carcinoma: A useful model for testing drugs. Clin Cancer Res 12: 4306-4314, 2006.

19. National Research Council (US) Committee for the Update of the Guide for the Care and Use of Laboratory Animals: Guide for the Care and Use of Laboratory Animals. 8th edition. National Academies Press, US, Washington, DC, 2011.

20. Huynh H, Chow PK, Palanisamy N, Salto-Tellez M, Goh BC, Lee CK, Somani A, Lee HS, Kalpana R, Yu K, et al: Bevacizumab and rapamycin induce growth suppression in mouse models of hepatocellular carcinoma. J Hepatol 49: 52-60, 2008.

21. Huynh H, Ngo VC, Koong HN, Poon D, Choo SP, Toh HC, Thng $\mathrm{CH}$, Chow P, Ong HS, Chung A, et al: AZD6244 enhances the anti-tumor activity of sorafenib in ectopic and orthotopic models of human hepatocellular carcinoma (HCC). J Hepatol 52: 79-87, 2010.

22. Huynh H, Lee LY, Goh KY, Ong R, Hao H-X, Huang A, Wang Y, Graus Porta D, Chow P and Chung A: Infigratinib mediates vascular normalization, impairs metastasis and improves chemotherapy in hepatocellular carcinoma. Hepatology: Dec 21, 2018 (Epub ahead of print).

23. Cervenka I, Wolf J, Mašek J, Krejci P, Wilcox WR, Kozubík A, Schulte G, Gutkind JS and Bryja V: Mitogen-activated protein kinases promote $\mathrm{WNT} /$ beta-catenin signaling via phosphorylation of LRP6. Mol Cell Biol 31: 179-189, 2011.

24. Brembeck FH, Rosário M and Birchmeier W: Balancing cell adhesion and Wnt signaling, the key role of beta-catenin. Curr Opin Genet Dev 16: 51-59, 2006.

25. Krejci P, Aklian A, Kaucka M, Sevcikova E, Prochazkova J, Masek JK, Mikolka P, Pospisilova T, Spoustova T, Weis M, et al: Receptor tyrosine kinases activate canonical WNT/ $\beta$-catenin signaling via MAP kinase/LRP6 pathway and direct $\beta$-catenin phosphorylation. PLoS One 7: e35826, 2012.

26. Hendriksen J, Fagotto F, van der Velde H, van Schie M, Noordermeer J and Fornerod M: RanBP3 enhances nuclear export of active (beta)-catenin independently of CRM1. J Cell Biol 171: 785-797, 2005 . 
27. Pokutta S and Weis WI: Structure of the dimerization and beta-catenin-binding region of alpha-catenin. Mol Cell 5 533-543, 2000.

28. de La Coste A, Romagnolo B, Billuart P, Renard CA, Buendia MA, Soubrane O, Fabre M, Chelly J, Beldjord C, Kahn A, et al: Somatic mutations of the beta-catenin gene are frequent in mouse and human hepatocellular carcinomas. Proc Natl Acad Sci USA 95: 8847-8851, 1998.

29. Miyoshi Y, Iwao K, Nagasawa Y, Aihara T, Sasaki Y, Imaoka S, Murata M, Shimano T and Nakamura Y: Activation of the beta-catenin gene in primary hepatocellular carcinomas by somatic alterations involving exon 3. Cancer Res 58: 2524-2527, 1998.

30. Laurent-Puig P and Zucman-Rossi J: Genetics of hepatocellular tumors. Oncogene 25: 3778-3786, 2006.

31. Katoh M: Canonical and non-canonical WNT signaling in cancer stem cells and their niches: Cellular heterogeneity, omics reprogramming, targeted therapy and tumor plasticity (Review). Int J Oncol 51: 1357-1369, 2017.

32. He TC, Sparks AB, Rago C, Hermeking H, Zawel L, da Costa LT, Morin PJ, Vogelstein B and Kinzler KW: Identification of c-MYC as a target of the APC pathway. Science 281: 1509-1512, 1998.

33. Pez F, Lopez A, Kim M, Wands JR, Caron de Fromentel C and Merle P: Wnt signaling and hepatocarcinogenesis: molecular targets for the development of innovative anticancer drugs. J Hepatol 59: 1107-1117, 2013.

34. Vilchez V, Turcios L, Marti F and Gedaly R: Targeting Wnt/ $\beta$-catenin pathway in hepatocellular carcinoma treatment. World J Gastroenterol 22: 823-832, 2016.

35. Delgado ER, Yang J, So J, Leimgruber S, Kahn M, Ishitani T, Shin D, Mustata Wilson G and Monga SP: Identification and characterization of a novel small-molecule inhibitor of $\beta$-catenin signaling. Am J Pathol 184: 2111-2122, 2014.

36. Gedaly R, Galuppo R, Daily MF, Shah M, Maynard E, Chen C, Zhang X, Esser KA, Cohen DA, Evers BM, et al: Targeting the Wnt $/ \beta$-catenin signaling pathway in liver cancer stem cells and hepatocellular carcinoma cell lines with FH535. PLoS One 9: e99272, 2014.

37. Handeli S and Simon JA: A small-molecule inhibitor of Tcf/beta-catenin signaling down-regulates PPARgamma and PPARdelta activities. Mol Cancer Ther 7: 521-529, 2008.

38. Galuppo R, Maynard E, Shah M, Daily MF, Chen C, Spear BT and Gedaly R: Synergistic inhibition of HCC and liver cancer stem cell proliferation by targeting RAS/RAF/MAPK and WNT/ $\beta$-catenin pathways. Anticancer Res 34: 1709-1713, 2014.

39. Lin $\mathrm{HH}$, Feng WC, Lu LC, Shao YY, Hsu CH and Cheng AL: Inhibition of the Wnt/ $\beta$-catenin signaling pathway improves the anti-tumor effects of sorafenib against hepatocellular carcinoma. Cancer Lett 381: 58-66, 2016.

40. Aberle H, Schwartz H, Hoschuetzky H and Kemler R: Single amino acid substitutions in proteins of the armadillo gene family abolish their binding to alpha-catenin. J Biol Chem 271: 1520-1526, 1996.
41. Roura S, Miravet S, Piedra J, García de Herreros A and Duñach M: Regulation of E-cadherin/Catenin association by tyrosine phosphorylation. J Biol Chem 274: 36734-36740, 1999.

42. Piedra J, Miravet S, Castaño J, Pálmer HG, Heisterkamp N, García de Herreros A and Duñach M: p120 Catenin-associated Fer and Fyn tyrosine kinases regulate beta-catenin Tyr-142 phosphorylation and beta-catenin-alpha-catenin Interaction. Mol Cell Biol 23: 2287-2297, 2003.

43. Piedra J, Martinez D, Castano J, Miravet S, Dunach M and de Herreros AG: Regulation of beta-catenin structure and activity by tyrosine phosphorylation. J Biol Chem 276: 20436-20443, 2001.

44. Brembeck FH, Schwarz-Romond T, Bakkers J, Wilhelm S, Hammerschmidt $\mathrm{M}$ and Birchmeier W: Essential role of BCL9-2 in the switch between beta-catenin's adhesive and transcriptional functions. Genes Dev 18: 2225-2230, 2004.

45. Li Y, Lu W, He X, Schwartz AL and Bu G: LRP6 expression promotes cancer cell proliferation and tumorigenesis by altering beta-catenin subcellular distribution. Oncogene 23: 9129-9135, 2004.

46. Austinat M, Dunsch R, Wittekind C, Tannapfel A, Gebhardt R and Gaunitz F: Correlation between beta-catenin mutations and expression of Wnt-signaling target genes in hepatocellular carcinoma. Mol Cancer 7: 21, 2008.

47. Boyault $S$, Rickman DS, de Reyniès A, Balabaud C, Rebouissou S, Jeannot E, Hérault A, Saric J, Belghiti J, Franco D, et al: Transcriptome classification of HCC is related to gene alterations and to new therapeutic targets. Hepatology 45: 42-52, 2007.

48. Cleary SP, Jeck WR, Zhao X, Chen K, Selitsky SR, Savich GL, Tan TX, Wu MC, Getz G, Lawrence MS, et al: Identification of driver genes in hepatocellular carcinoma by exome sequencing. Hepatology 58: 1693-1702, 2013.

49. Guichard C, Amaddeo G, Imbeaud S, Ladeiro Y, Pelletier L, Maad IB, Calderaro J, Bioulac-Sage P, Letexier M, Degos F, et al: Integrated analysis of somatic mutations and focal copy-number changes identifies key genes and pathways in hepatocellular carcinoma. Nat Genet 44: 694-698, 2012.

50. Kan Z, Zheng H, Liu X, Li S, Barber TD, Gong Z, Gao H, Hao K, Willard MD, Xu J, et al: Whole-genome sequencing identifies recurrent mutations in hepatocellular carcinoma. Genome Res 23: 1422-1433, 2013.

51. Aberle H, Bauer A, Stappert J, Kispert A and Kemler R: beta-catenin is a target for the ubiquitin-proteasome pathway. EMBO J 16: 3797-3804, 1997.

52. Liu C, Li Y, Semenov M, Han C, Baeg GH, Tan Y, Zhang Z, Lin X and $\mathrm{He} \mathrm{X}$ : Control of beta-catenin phosphorylation/degradation by a dual-kinase mechanism. Cell 108: 837-847, 2002.

53. Orford K, Crockett C, Jensen JP, Weissman AM and Byers SW: Serine phosphorylation-regulated ubiquitination and degradation of beta-catenin. J Biol Chem 272: 24735-24738, 1997. 